Article

\title{
Cytotoxicity Induction by the Oxidative Reactivity of Nanoparticles Revealed by a Combinatorial GNP Library with Diverse Redox Properties
}

\author{
Shenqing Wang ${ }^{1}$, Xiliang Yan ${ }^{2}$, Gaoxing Su ${ }^{3}$ and Bing Yan ${ }^{2, *}$ \\ 1 School of Chemistry and Chemical Engineering, Shandong University, Jinan 250100, China; \\ wang_shen_qing@163.com \\ 2 Key Laboratory for Water Quality and Conservation of the Pearl River Delta, Institute of Environmental \\ Research at Greater Bay, Ministry of Education, Guangzhou University, Guangzhou 510006, China; \\ yanxiliang1991@gzhu.edu.cn \\ 3 School of Pharmacy, Nantong University, Nantong 226001, China; sugaoxing@ntu.edu.cn \\ * Correspondence: drbingyan@gzhu.edu.cn; Tel.: +86-0531-8836-6232
}

check for updates

Citation: Wang, S.; Yan, X.; Su, G.; Yan, B. Cytotoxicity Induction by the Oxidative Reactivity of Nanoparticles Revealed by a Combinatorial GNP Library with Diverse Redox Properties. Molecules 2021, 26, 3630. https://doi.org/10.3390/ molecules 26123630

Academic Editors: Marco Baron, Cristina Tubaro and Andrea Biffis

Received: 7 May 2021

Accepted: 8 June 2021

Published: 14 June 2021

Publisher's Note: MDPI stays neutral with regard to jurisdictional claims in published maps and institutional affiliations.

Copyright: (c) 2021 by the authors. Licensee MDPI, Basel, Switzerland. This article is an open access article distributed under the terms and conditions of the Creative Commons Attribution (CC BY) license (https:// creativecommons.org/licenses/by/ $4.0 /)$.

\begin{abstract}
It is crucial to establish relationship between nanoparticle structures (or properties) and nanotoxicity. Previous investigations have shown that a nanoparticle's size, shape, surface and core materials all impact its toxicity. However, the relationship between the redox property of nanoparticles and their toxicity has not been established when all other nanoparticle properties are identical. Here, by synthesizing an 80-membered combinatorial gold nanoparticle (GNP) library with diverse redox properties, we systematically explored this causal relationship. The compelling results revealed that the oxidative reactivity of GNPs, rather than their other physicochemical properties, directly caused cytotoxicity via induction of cellular oxidative stress. Our results show that the redox diversity of nanoparticles is regulated by GNPs modified with redox reactive ligands.
\end{abstract}

Keywords: nano-combinatorial chemistry; gold nanoparticle; redox; nanotoxicity; QSAR

\section{Introduction}

The rapid increase in the application of nanomaterials in consumer products, biomedical materials, and industries, is a result of the vast diversity of their structural properties. Gold nanoparticles (GNPs) have been the object of investigations for usages as contrast agents for computed tomography, as drug delivery vehicles and as agents for photothermal cancer therapy, despite having no FDA approval yet. This presents a major challenge for effective and timely screening for their potential adverse effects in biological and environmental systems [1-4]. The inherent properties of nanoparticles, including size, shape, chemical composition, surface functionalization, solubility, hydrophobicity, surface charge and agglomeration state may all affect their interactions with biomolecules and cells [5-7]. Therefore, these physicochemical factors can determine the bioactivity and toxicity of nanoparticles [8-11].

Previous reports have focused on the influences of certain physicochemical properties of nanoparticles, such as size, surface chemistry and shape or core composition, on cytotoxicity [12-14]. More solid conclusions were achieved for the effects of nanoparticle size and surface chemistry. The effects of core composition on cellular perturbations were recently reported by us [15], and studies on the influence of shape have also been published [16-18]. However, as an intrinsic property of all nanoparticles, the effects of the redox reactivity of nanoparticles on cellular perturbations have not been systematically studied. Attribution of physicochemical determinants of nanoparticles to their toxicity is complex and requires systematical investigations because all these factors may participate in biological regulation simultaneously [19-21]. Therefore, it is difficult to solve this problem without systematic 
and isolated studies because of the lack of comparability. Facing this challenge, we developed a nano-combinatorial nanoparticle library approach and solved issues related to surface chemistry, size and core material. These systematic studies provided more convincing results [22-24].

In this study, we explored the relationship between the redox reactivity of nanoparticles and cellular perturbations using a combinatorial GNP library with diverse redox properties. In this systematic work, the redox-diversified library was first synthesized by incorporating a ferrocene moiety and organic ligand molecules with diversified structures. Cellular studies then demonstrated that the redox reactivity of GNPs, rather than other physicochemical properties, causes cytotoxicity via induction of cellular oxidative stress.

\section{Results and Discussion}

\subsection{Combinatorial GNP Library with Diversified Redox Properties}

In order to model the naturally diverse redox properties of nanoparticles, we designed a combinatorial GNP library. A ferrocene group was introduced into each ligand molecule on the surface of GNPs. Ferrocene can undergo redox reactions repeatedly with oxidative or reductive species in human cells [25-27]. These reactions are through the reversible transformation of $\mathrm{Fe}(\mathrm{II})$ and $\mathrm{Fe}(\mathrm{III})$ with the loss and gain of electrons. Moreover, the redox activity of the ferrocene group is probably affected by the ligand structure so that redox activities of GNPs may be modulated. In line with these designs, we initiated the synthesis of a combinatorial GNP library following Scheme 1.

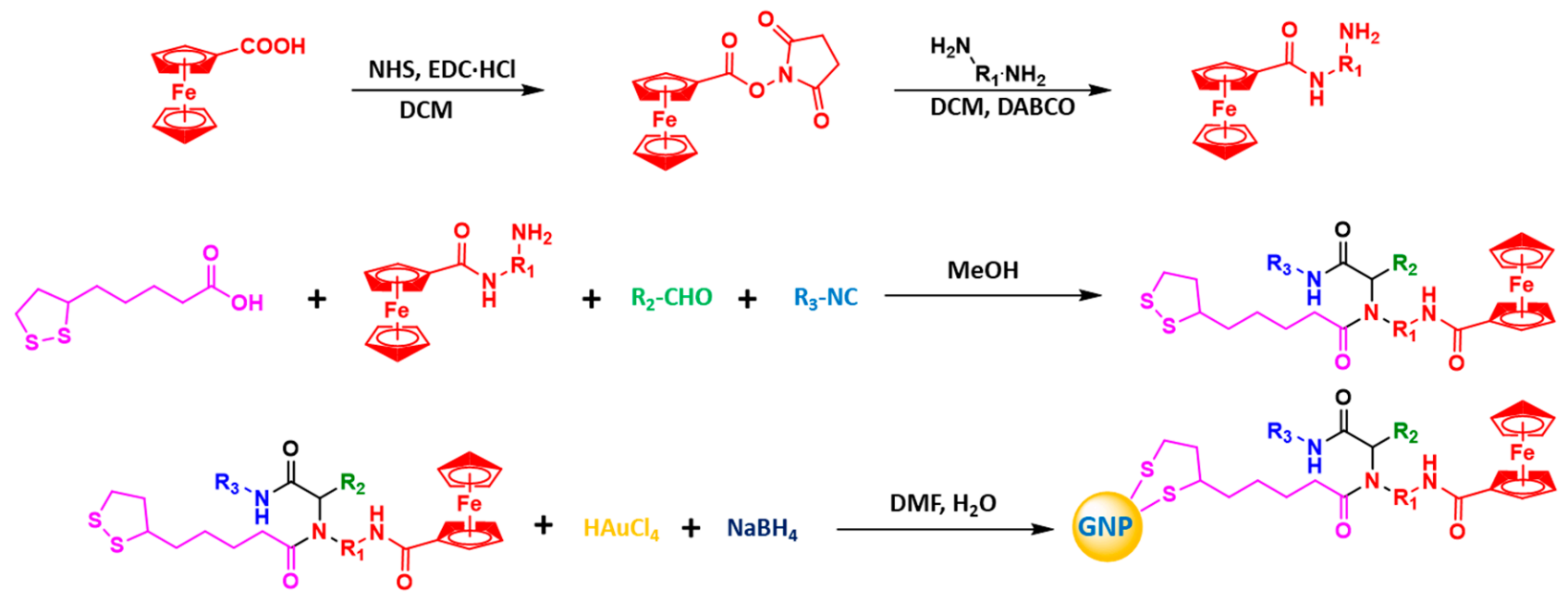

Scheme 1. Synthesis of the combinatorial GNP library. Using the Ugi multicomponent reaction, ligand molecules with a ferrocene group and various molecules structures were synthesized before a combinatorial GNP library with various redox activities was constructed using these ligands.

The key to success in this study was to first design diverse ligand molecules that could modulate the ferrocene group and therefore the redox activity of the GNPs. With this in mind, we introduced linear and cyclic substituent structures to diversify the influence of molecule geometry and introduced aromatic ring structures with different substituents to reflect the influence of $\pi$ electron density. The introduction of heteroatoms reflected the effect of hydrophilicity and hydrogen bond acceptors, the amino and carboxyl groups reflected the influence of charge and the hydroxyl groups reflected the influence of hydrogen bond donors (Figure 1). 


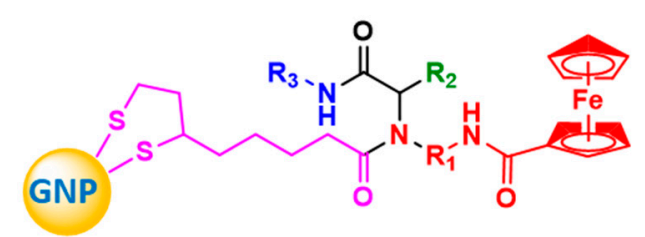

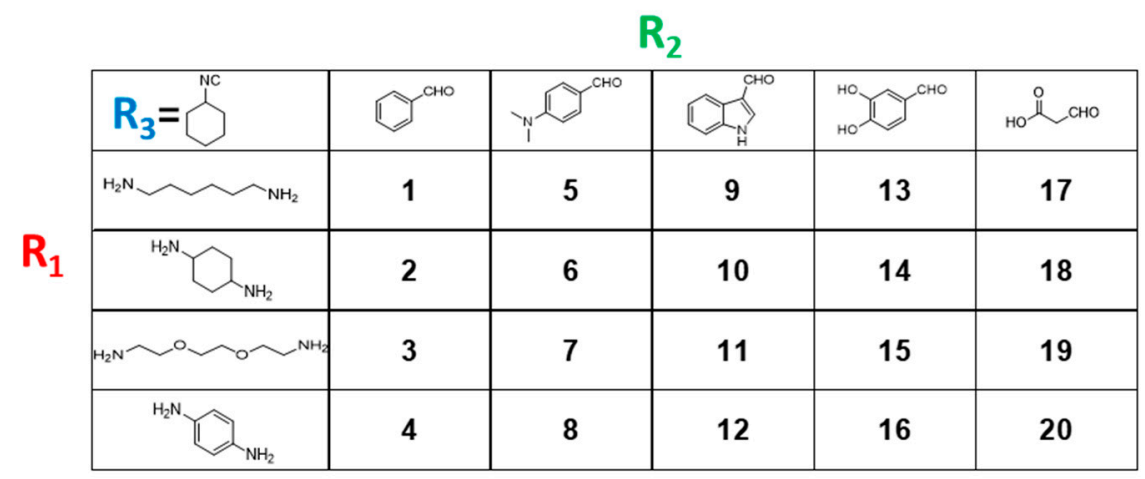

\begin{tabular}{|c|c|c|c|c|c|}
\hline \multicolumn{6}{|c|}{$\mathbf{R}_{2}$} \\
\hline $\mathbf{R}_{\mathbf{3}}=\stackrel{\mathrm{NC}}{\uparrow}$ & $\mathbb{1 0} y^{\text {cho }}$ & N1) & $\mathbb{C O S}_{\mathrm{H}}^{0}$ & ${ }^{\mathrm{HO}} \mathrm{NO}^{\mathrm{CHO}}$ & но英 сно \\
\hline${ }^{H_{2} N} \sim$ & 21 & 25 & 29 & 33 & 37 \\
\hline & 22 & 26 & 30 & 34 & 38 \\
\hline${ }_{2} \mathrm{~N} \sim \mathrm{O} \sim \mathrm{O} \sim \mathrm{NH}_{2}$ & 23 & 27 & 31 & 35 & 39 \\
\hline & 24 & 28 & 32 & 36 & 40 \\
\hline
\end{tabular}

\begin{tabular}{|c|c|c|c|c|c|}
\hline \multicolumn{6}{|c|}{$\mathbf{R}_{2}$} \\
\hline $\mathbf{R}_{3}=$ † & (1) & 岱 & 1) & ${ }_{\mathrm{HO}}^{\mathrm{HO}} \mathrm{O}^{\mathrm{CHO}}$ & 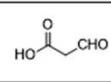 \\
\hline $\mathrm{H}_{2} \mathrm{~N} \sim \mathrm{NH}_{2}$ & 41 & 45 & 49 & 53 & 57 \\
\hline & 42 & 46 & 50 & 54 & 58 \\
\hline${ }_{2} \mathrm{~N}_{\mathrm{N}} \sim \mathrm{O}_{\mathrm{O}} \sim \mathrm{NH}_{2}$ & 43 & 47 & 51 & 55 & 59 \\
\hline & 44 & 48 & 52 & 56 & 60 \\
\hline
\end{tabular}

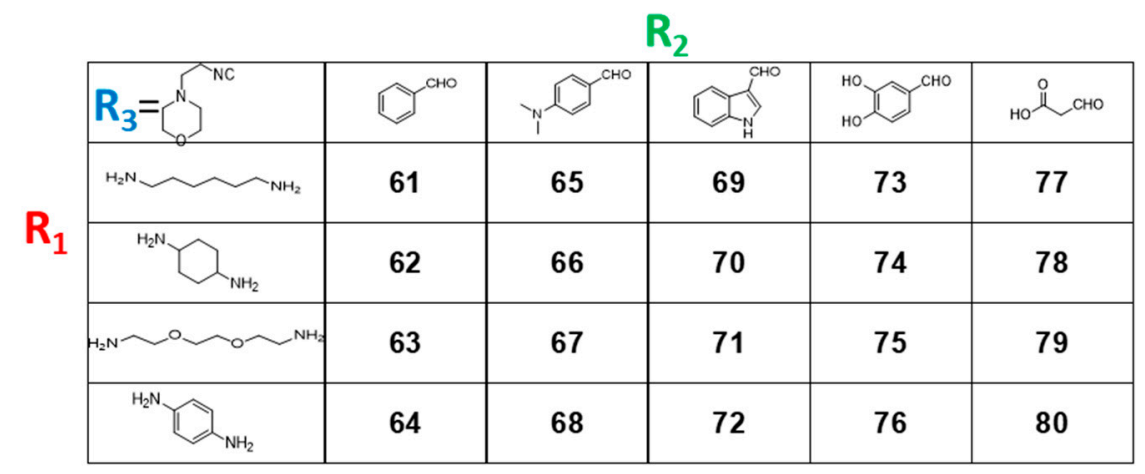

Figure 1. The numbering of 80 GNPs in the combinatorial GNP library. Based on the strategy of combinatorial chemistry, the surface physicochemical properties of GNPs were regulated by diverse ligand molecules. Five aldehyde compounds, four amino compounds and four isonitriles were used in the synthesis, resulting in a total of 80 GNPs. 


\subsection{Characterization of Physiochemical Properties of the GNP Library}

The GNP library was fully characterized for the GNPs' physicochemical properties. Morphologies of GNPs were determined by TEM (Figure 2a and Figure S1). The GNPs had a spherical shape and uniform diameter. The average diameter of the entire library was $5.6 \pm 0.5 \mathrm{~nm}$ (Figure $2 \mathrm{~b}$ ). In solution, GNPs were well dispersed with a slight aggregation tendency. Electrostatic and electrodynamic properties of GNPs were assessed by their zeta potential, which was on average $-24.8 \pm 9.1 \mathrm{mV}$ (Figure $2 \mathrm{~d}$ and Figure S2b).

a

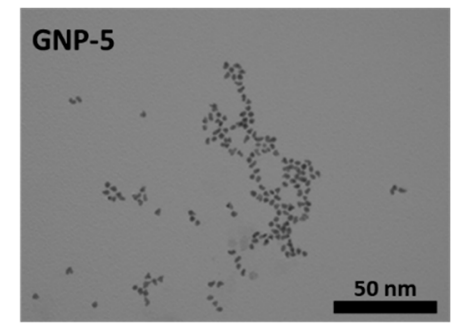

C

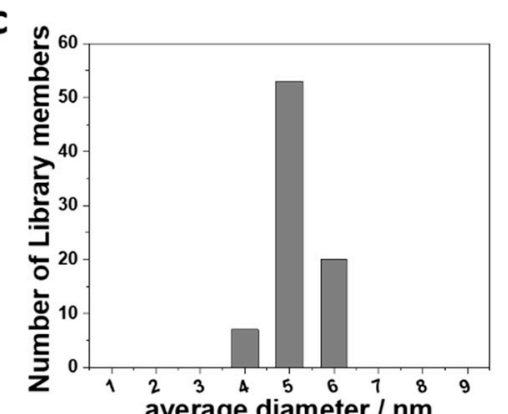

e

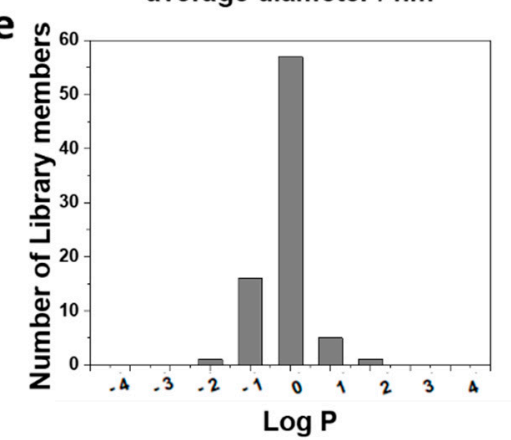

b

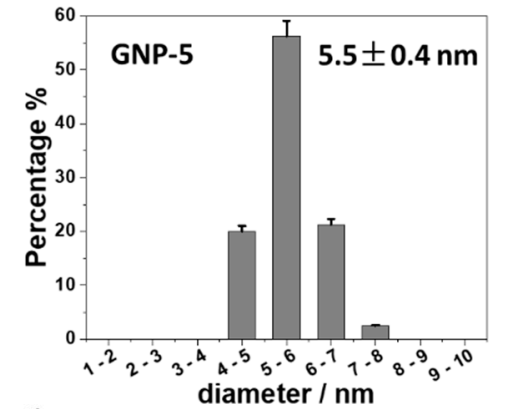

d

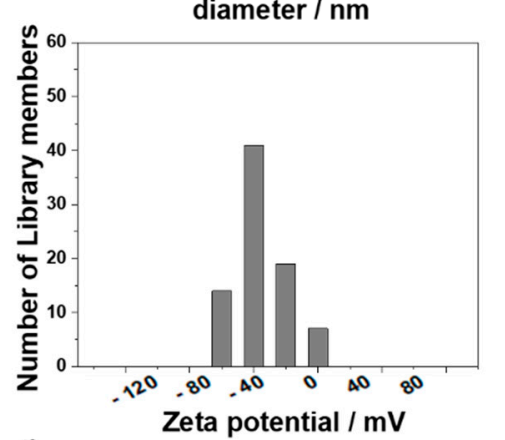

f

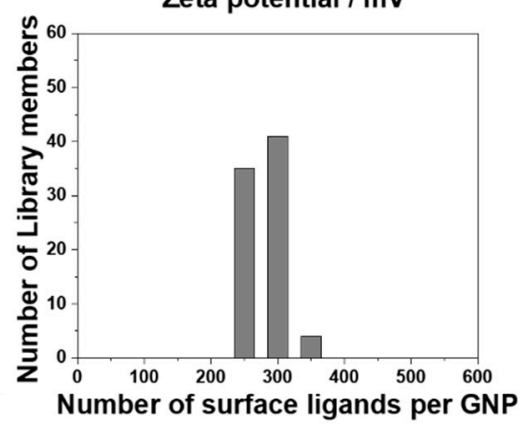

Figure 2. An overview of the basic physical and chemical properties of the GNP library. (a) TEM characterization of library gold nanoparticles (GNP-5 as an example) with a magnification of $\times 100,000$. (b) The average particle size distribution for GNP-5 was $5.5 \pm 0.4 \mathrm{~nm}$. (c) The average particle size distribution for all GNPs in the whole library. TEM data for GNPs in the whole library were in the range of $4.5 \sim 6.2 \mathrm{~nm}$. (d) The distribution of zeta potential values of the GNP library. (e) The distribution of $\log p$ values for the whole GNP library determined by the "shaking flask" method. (f) The distribution of surface ligand numbers per GNP across the whole GNP library determined by ICP-MS.

The hydrophobicity of a GNP determines its ability to penetrate cell membranes or bind to important biomolecules. This reactivity is characterized by GNPs' water/octanol participation coefficient or $\log p$ value. The $\log p$ values of all GNPs were determined with a modified "shaking flask" method [28-30]. Log $p$ values of the 80 GNPs in this library were between -1.0 and 1.0 and the average was $0.59 \pm 0.24$ (Figure 2e and Figure S2a). 


\subsection{Direct In Situ Quantification of the GNP Surface Modifications}

GNP properties, in large part, are determined by the surface ligand molecules or surface chemistry. However, determination of the number of surface ligands is not an easy task, especially in high-throughput screening. In most previous papers, this was not reported. In others, various analytical methods were applied, such as elemental analysis [31], thermogravimetric analyses [32] or cleavage and analysis methods [33]. For a large nanoparticle library or ligand molecules with multiple common elements, the applications of the above methods are limited. In this work, we established a direct, quick and accurate method to obtain both the number of ligands on each GNP and the number of GNPs in solution. By incorporating the ferrocene group in every ligand, we achieved both of the above goals using ICP-MS analysis (Scheme 2).

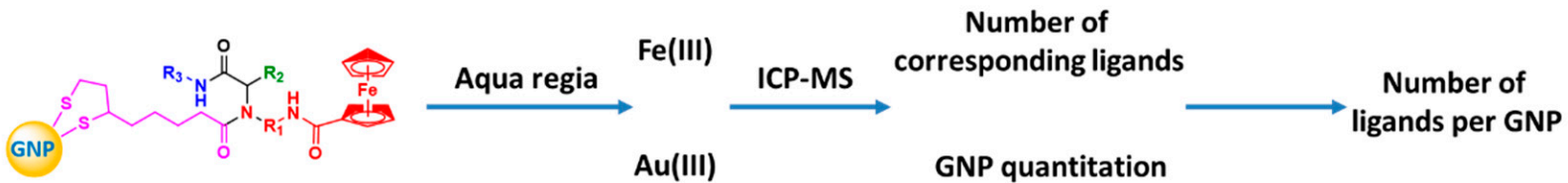

Scheme 2. One step determination of the number of ligands per GNP. The concentrations of Au(III) and Fe(III) were quantitatively determined by ICP-MS. The concentration of total GNPs was determined according to the Au content, and the total number of ligands was determined according to the Fe content. The loaded ligands per nanoparticle could then be obtained.

In our method, the concentrations of $\mathrm{Au}$ and Fe were simultaneously determined by ICP-MS in one step analysis, and the number of GNPs and number of ligands were calculated accordingly. The number of loaded ligands per GNP was the ratio of the ligand number to GNP number. For the GNP library, the number of ligands per GNP was in the range of 240 359 (Figure $2 \mathrm{f}$ and Figure S2C). Compared with the previous methods, our method involves fewer samples, simpler operation, fewer steps, reduces the possibility of error and is suitable for high-throughput characterization of a large number of nanoparticle samples.

\subsection{Diverse Redox Activities of the GNP Library and Underlying Mechanisms}

The ferrocene group offers GNPs a unique electron exchange ability. These GNPs can thus be expected to have electrochemical reactivities. Diverse molecule structures of ligands create different microenvironments, so the electrochemical reactivities of GNPs may be highly diverse. Such reactivities of GNPs were determined by cyclic voltammetry using the electrocatalytic reduction of $\mathrm{H}_{2} \mathrm{O}_{2}$. Different GNPs exhibited different intensities of reduction peak currents produced by $\mathrm{H}_{2} \mathrm{O}_{2}$ because of their different $\mathrm{H}_{2} \mathrm{O}_{2}$ reducing abilities. The ferrocene group surrounded by each individual molecular environment determined the redox activity of GNPs (Figure S3). The peak current is defined as the current density at $-0.20 \mathrm{~V}(\mathrm{Ag} / \mathrm{AgCl})$ as shown in Figure 3a. Cyclic voltammetry and the peak currents of all GNPs were experimentally determined (Figure $3 \mathrm{~b}$ and Figure S4). The peak current values of the GNP library varied, ranging from -0.04 to $-0.23 \mathrm{~mA}$, suggesting their different $\mathrm{H}_{2} \mathrm{O}_{2}$ reducing abilities [34-37]. After uptake by cells, GNPs with a stronger reducing ability will convert more $\mathrm{H}_{2} \mathrm{O}_{2}$ into $\mathrm{OH}^{-}$, which is relatively nontoxic [38-41]. In this process, the levels of ROS in cells are inhibited better, thus avoiding the occurrence of oxidative stress and cell damage. 

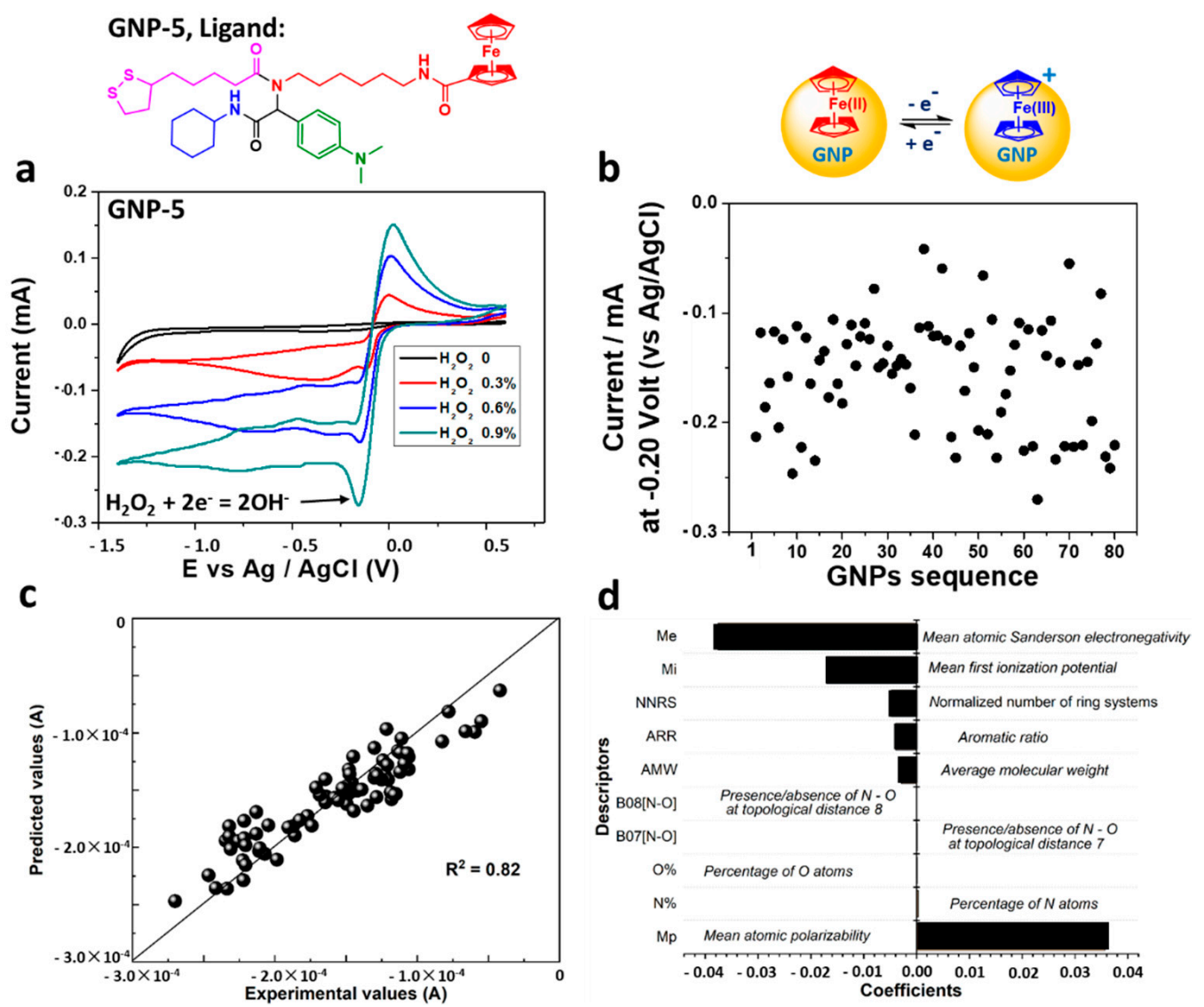

Figure 3. Diverse redox reactivities of the GNP library. (a) With GNP-5 as an example, the reduction activities of GNPs were determined by cyclic voltammetry and electro-catalytic decomposition of hydrogen peroxide $\left(\mathrm{H}_{2} \mathrm{O}_{2}+2 \mathrm{e}^{-}=2 \mathrm{OH}^{-}\right)$. Nanoparticles with the same concentration $(1.0 \mathrm{mg} / \mathrm{mL}$, $10 \mu \mathrm{L}$ ) were added to the surface of the glassy carbon electrode. The catalytic activity of GNPs was determined by the decomposition rate (current density) of hydrogen peroxide under specific voltage (GNP-5 as a model). (b) Diverse redox reactivities of the GNPs in the library. Absolute values of the experimental data for the whole library were in range of $0.04 \sim 0.27 \mathrm{~mA}$. (c) Correlations between experimental reduction values and multi-linear regression model predictions. The line of $\mathrm{y}=\mathrm{x}$ and the coefficient of determination $\left(R^{2}\right)$ are also shown in the plot. (d) Contributions of the top 10 Dragon descriptors from the modeling results. The descriptors were ranked based on the coefficients of the model. A description of each descriptor is also shown.

Furthermore, we explored how the structural features of surface ligands actually regulated the reduction activity of GNPs by analyzing the resulting predictive model. Based on the coefficients of each variable in the model, the top seven ranked descriptors were selected and are shown in Figure $3 \mathrm{~d}$. The high ranking of a descriptor use indicated its critical contribution to the final modeling and the reduction activity of GNPs. Therefore, the reduction activity of GNPs was mostly relevant to the mean atomic electronegativity and mean atomic polarizability. Electronegativity is the tendency of an atom to attract shared electrons to itself, and polarizability is defined as the dipole moment induced in the atom in response to the application of an electric field. Obviously, the distribution of electrons or electron clouds inside atoms greatly affects the reduction activity of GNPs, while these properties are significantly enhanced by ligand structural diversity. The properties (physical and chemical properties and reactivity) of molecules are determined by their molecular orbitals and the arrangement of electrons in the molecular orbitals. The structural diversity of ligands inevitably affects the composition of molecular orbitals and the energy levels of the HOMO and LUMO, modulating the physical and chemical properties and reactivity of molecules and GNPs. Previous studies have also shown that the electronegativity and 
polarizability of atoms are closely related to the reduction activity of materials [42,43]. The model constructed here and the corresponding mechanism analysis can help us design nanomaterials with the required reduction activity in the future. Based on the theoretical calculation of the quantum chemistry, the weight of many influencing factors can be summarized and analyzed so as to realize the effect prediction of nanomaterials and the auxiliary design of new nanomaterials.

\subsection{Redox Activities of GNPs Induce Cytotoxicity via Regulating the Cellular Oxidative Stress}

In order to examine whether the redox activity and other physicochemical properties of GNPs play a role in inducing cellular perturbations, we determined cellular uptake (Figure $4 \mathrm{~b}$ and Figure S2d), cellular oxidative stress (Figure S2e) and cytotoxicity along with their relationships with GNP properties. The GNP-induced changes in relative fluorescence intensity of the DCFH-DA probe reflected the level of cellular oxidative stress. There was a clear trend that cellular oxidative stress was positively correlated with the oxidative properties of GNPs (Figure 4e). GNP-induced cytotoxicity was determined with the CellTiter-Glo ${ }^{\circledR}$ assay (Figure $4 \mathrm{~d}$ and Figure S5). GNP concentration that induced 50\% cell death (EC50) was used to reflect cytotoxicity. The redox activity of the GNP library was correlated with cytotoxicity, with more oxidative GNPs inducing more cytotoxicity. It is well-known that $\mathrm{H}_{2} \mathrm{O}_{2}$ is one of the important $\mathrm{ROS}$ species in cells [44-46]. Combining the above results, GNP-induced cellular oxidative stress was positively correlated with cytotoxicity (the lower the EC50 values, the higher the cytotoxicity). Excessive ROS in cells may result in random oxidation of nucleic acids, proteins and lipids, which may lead to the loss of their normal functions by changing the structure of these biomolecules [47-51]. When this kind of damage exceeds the self-healing ability of cells, it induces programmed cell death.

To examine whether other basic physicochemical properties of GNPs play a role in GNP-induced oxidative stress in cells, the effects of hydrophobic properties, zeta potential, cellular uptake and surface ligand loading were analyzed. Our results showed that the number of surface ligands (Figure S6), hydrophobic properties (Figure 4a and Figure S7), zeta potential (Figure 4c and Figure S7) and cellular uptake (Figure 4b) did not have any correlation with the induction of cellular oxidative stress or cytotoxicity in A549 cells. Therefore, the diverse redox activities of GNPs were the only reason for cytotoxicity via induction of cellular oxidative stress.

The 80 GNP library members were all modified by organic ligand molecules. Although ligands were diverse, they hardly altered some of the basic physical properties, such as the hydrophobicity and the zeta potential. However, these structural diversities were enough to change the redox reactivities of the GNPs and, therefore, the induction of cellular oxidative stress and cytotoxicity. The GNP library approach has been used previously to develop cancer cell-targeting nanoparticles [22] and cellular oxidative stress-enhancing nanoparticles [52]. 

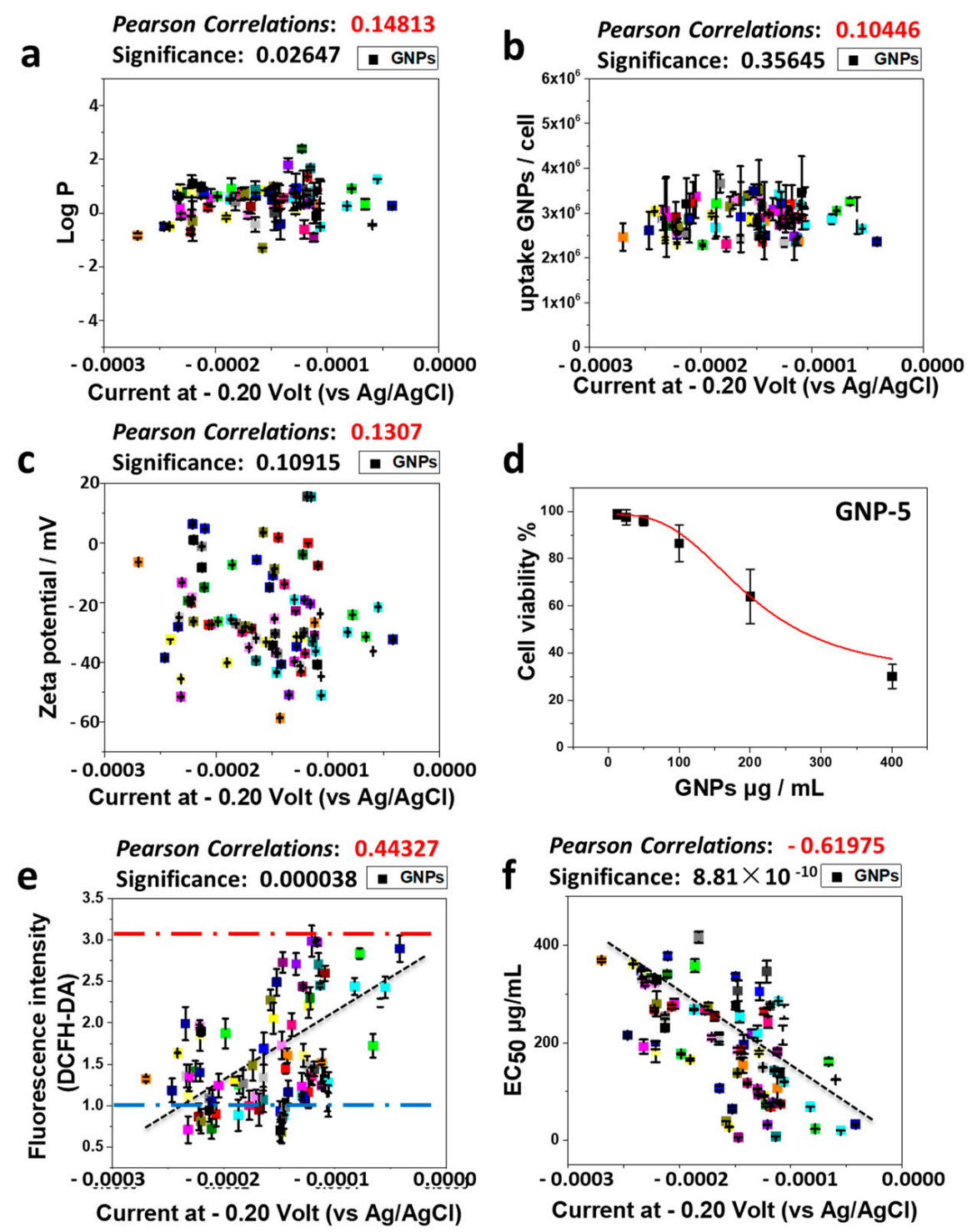

Figure 4. The relationship between the redox activity of GNPs and their physicochemical or biological properties. (a) The change of redox activity of GNPs did not alter the hydrophobicity of GNPs. (b) Furthermore, there was no effect on the cell uptake of GNPs. (c) The redox activity was independent of the surface charge state (zeta potential) of GNPs. (d) With GNP-5 as an example, the dose-dependent cytotoxicity of A549 cells is shown. (e) There was a positive correlation between the level of cellular oxidative stress and the oxidative activity of GNPs. Blue dotted line: negative control; red dotted line: positive control; black dotted line: change trend. (f) A negative correlation between EC50 values (or a positive correlation between cytotoxicity) and the oxidative activity of GNPs. Black dotted line: change trend.

\section{Materials and Methods}

\subsection{Chemicals}

Lipoic acid $(97 \%)$, petroleum ether $(99 \%)$, triethylamine $(98 \%)$, tetrahydrofuran $(97 \%)$, ethanol $(99 \%)$, ethyl acetate $(99 \%)$, dichloromethane $(97 \%)$, 1-octanol $(\geq 85 \%)$, $\mathrm{N}$-dimethylformamide $(\geq 97 \%)$, sodium bicarbonate $(\geq 95 \%)$, sodium chloride $(90 \%)$, sodium hydroxide ( $\geq 97 \%)$, hydrochloric acid $(98 \%)$, sodium borohydride $(95 \%)$, hydrogen peroxide (30\%) and chloroauric acid (99\%) were purchased from Sigma-Aldrich (St. Louis, MO, USA). 


\subsection{Synthesis of Ligands}

In an ice bath, $11.5 \mathrm{~g}(0.05 \mathrm{~mol})$ of ferrocenecarboxylic acid was mixed with $100 \mathrm{~mL}$ of dichloromethane (DCM). Under vigorous stirring, $7.0 \mathrm{~g}(0.06 \mathrm{~mol})$ of $\mathrm{N}$-hydroxysuccinimide (NHS) and $11.5 \mathrm{~g}(0.06 \mathrm{~mol})$ of 3-ethylcarbodiimide hydrochloride (EDC $\cdot \mathrm{HCl})$ were added to the reaction system. The reaction was stirred for $4-6 \mathrm{~h}$ in an ice bath and monitored by TLC. After reaction, filtration was carried out and a DCM solution of (1) was obtained.

In an ice bath, $8.5 \mathrm{~g}(0.075 \mathrm{~mol})$ of triethylenediamine was added to $50 \mathrm{~mL}$ of DCM. Then, $24.6 \mathrm{~mL}$ of 1,4-cyclohexanediamine was added and stirred until the reaction system was uniformly stabilized. The DCM solution (1) was added dropwise to the reaction system within 2 to $3 \mathrm{~h}$. The reaction was maintained continuously for $24 \mathrm{~h}$. The reaction system gradually became viscous and the reaction was monitored by TLC. After reaction, the solvent was removed by rotary evaporation, and the crude product was washed repeatedly with water and purified by column chromatography. An orange-red solid product (2) was obtained.

Intermediate (2) $(0.75 \mathrm{~g}, 5 \mathrm{mmol})$, benzaldehyde $(0.50 \mathrm{~mL}, 5 \mathrm{mmol})$, cyclohexyl isocyanide $(0.60 \mathrm{~mL}, 5 \mathrm{mmol})$ and lipoic acid $(1.03 \mathrm{~g}, 5 \mathrm{mmol})$ were added to $10 \mathrm{~mL}$ of methanol and reacted at $320 \mathrm{~K}$ for $48 \mathrm{~h}$. The reaction was monitored by TLC. After reaction, the solvent was removed by rotary evaporation, the crude product was purified by column chromatography and ligand 1 was obtained.

Ligand 1 was an orange-red solid with a yield of $54.11 \% ;{ }^{1} \mathrm{H}$ NMR $(500 \mathrm{MHz}$, DMSO$\left.\mathrm{d}_{6}\right) \delta(\mathrm{ppm})=8.45(\mathrm{~s}, 1 \mathrm{H}), 8.05(\mathrm{~s}, 2 \mathrm{H}), 7.9$ to $7.5(\mathrm{~m}, 5 \mathrm{H}), 4.53(\mathrm{~m}, 1 \mathrm{H}), 3.34(\mathrm{~m}, 1 \mathrm{H}), 3.01(\mathrm{t}$, $1 \mathrm{H}), 2.6(\mathrm{~m}, 3 \mathrm{H}), 2.1$ to $1.1(\mathrm{~m}, 27 \mathrm{H}) ; \mathrm{C}_{27} \mathrm{H}_{41} \mathrm{~N}_{3} \mathrm{O}_{3} \mathrm{~S}_{2}$; ESI-MS: $\mathrm{m} / \mathrm{z} 730.3(\mathrm{M}+1)^{+}$.

\subsection{Synthesis of the GNP Library}

We mixed an orange solution containing $0.0032 \mathrm{mmol}$ of ligand (Ligand 1) in $20 \mathrm{~mL}$ of DMF, $12.5 \mathrm{mg}$ of $\mathrm{HAuCl}_{4} \cdot 3 \mathrm{H}_{2} \mathrm{O}, 0.6 \mathrm{mg}$ of ammonium chloride and $0.95 \mathrm{mg}$ of sodium citrate in $2.25 \mathrm{~mL}$ of water at room temperature. Then, in an ice bath with vigorous stirring, $15 \mathrm{mg}$ of sodium borohydride in $15 \mathrm{~mL}$ of water was slowly added to the reaction system through peristaltic pumping over $60 \mathrm{~min}$. The solution color became dark and then red gradually. GNPs were named from GNP-1 to GNP-80 according to the types of modified ligands. After the Ugi reaction, 80 different ligands were obtained. Each ligand molecule had only one ferrocene group (one iron atom) with the "labeling" of the ligands undertaken by using the Fe atom.

\subsection{Measurements of Zeta Potentials of GNPs}

GNPs were suspended in aqueous solution with sonication. The zeta potentials of GNPs were measured at room temperature using a Malvern Zetasizer instrument (Nano ZS90, Malvern Instruments Ltd., Worcestershire, UK). All samples were measured at the same concentration. Each sample was measured in triplicate. The samples were diluted with Milli-Q water with a $\mathrm{pH}$ value of 6.83 when measuring zeta potential. Amine groups in the starting materials were converted to amides after the reactions so that there were no amine groups in the final products.

\subsection{Determination of Loaded Ligands on GNPS}

GNPs were suspended in aqueous solution with sonication. Then, $50 \mu \mathrm{L}$ of GNP solution was mixed with $1.0 \mathrm{~mL}$ of aqua regia. The sample was completely digested and diluted with Milli-Q. The contents of gold and iron were determined by ICP-MS (Varian 820-MS). The GNP concentration was determined by the Au concentration, and the ligand concentration was determined by the Fe concentration.

GNPs can be approximately regarded as spheres. The gold atom number in a spherical GNP with a specific particle size can be calculated $\left(\mathbf{m}_{\mathrm{Au}} \cdot N_{\mathrm{A}}=M_{\mathrm{Au}}, \mathbf{m}_{\mathrm{Au}} \cdot \mathbf{n}_{\mathrm{Au}}=\mathbf{m}_{\mathrm{GNP}}=\right.$ $\left.\rho_{\mathrm{Au}} \cdot \mathrm{V}_{\mathrm{GNP}}\right)$. Therefore, the results of ICP-MS can reflect the number of GNPs in a specific 
volume of GNP solution. In addition, the number of iron atoms is equal to the number of ligands $\left(\mathbf{n}_{\mathbf{F e}}=\mathbf{n}_{\text {Ligand }}\right)$.

$$
\text { Number of ligands }=\left(C_{\mathrm{Fe}} / M_{\mathrm{Fe}}\right)\left(C_{\mathrm{Au}} M_{\mathrm{Au}}\right)^{-1} \cdot\left(\rho_{\mathrm{Au}} \cdot \mathrm{V}_{\mathrm{GNP}} N_{\mathrm{A}} M_{\mathrm{Au}}\right)
$$

An example of such analysis can be shown for GNP-5: the volume of GNP-5 was $87 \mathrm{~nm}^{3}\left(\mathbf{V}=4 / 3 \cdot \pi \cdot \mathbf{r}^{3}\right)$ since the average particle diameter was $5.5 \mathrm{~nm}$ (Figure 2a). $\rho_{\text {Au }}=19.32 \mathrm{~kg} / \mathrm{m}^{3}$. Based on the ICP-MS results, the Au content was $146.51 \mathrm{ppb}$ and the Fe content was $2.73 \mathrm{ppb}$ (all results after deducting the background value). Using Equation (1), we were able to determine that the number of ligands loaded on GNP-5 was 337.

\subsection{TEM Images Characterization}

TEM images of the GNPs were taken using a JEOL-1011 transmission electron microscope (JEM, Tokyo, Japan) at $100 \mathrm{KV}$. The images were acquired using an AMT 2k CCD camera. Image data were analyzed by ImageJ.

\subsection{Hydrophobicity Measurements of GNPs}

An equal volume of deionized water and n-octanol were mixed and stirred for $24 \mathrm{~h}$. The mixture solution was allowed to stand quietly. After the separation, the upper layer was the water-saturated n-octanol, and the lower layer was the n-octanol-saturated aqueous solution. The two phases were collected and used in the next step.

Hydrophobicity of GNPs was measured according a previously reported method. Firstly, $0.3 \mathrm{mg}$ of GNPs was dispersed with $1.0 \mathrm{~mL}$ of n-octanol-saturated aqueous solution. Secondly, $1.0 \mathrm{~mL}$ of water-saturated n-octanol was added. Thirdly, the mixtures were vigorously shaken on a shaker for $24 \mathrm{~h}$. After that, the mixtures were left to stand quietly until the two phases were completely separated. Each phase was carefully collected and dried at $120{ }^{\circ} \mathrm{C}$ under vacuum for $4 \mathrm{~h}$. Finally, $500 \mu \mathrm{L}$ of fresh aqua regia was added to digest GNPs over $12 \mathrm{~h}$. After diluting, gold concentrations in each phase were measured by ICP-MS. Log $p$ values of GNPs were calculated according to the gold concentrations in the two phases.

\subsection{Preparation of GNP Solution for Cell-Based Experiments}

The aqueous dispersion of the gold nanoparticles was sonicated for $15 \mathrm{~min}$. Sterile water was then added to dilute GNPs to a concentration of $1.0 \mathrm{mg} / \mathrm{mL}$, and uniformly dispersed stock solutions were obtained. After sterilization by batch sterilization, stock solutions were stored at $4{ }^{\circ} \mathrm{C}$ before use. For cell experiments, after sonication, stock solutions were diluted with cell culture medium to desired concentrations and vortexed before adding to plate wells.

\subsection{Cytotoxicity Test}

A549 cells were cultured with RPMI 1640 medium and, respectively, supplemented with $10 \%$ fetal bovine serum, $100 \mathrm{U} / \mathrm{mL}$ penicillin and $100 \mu \mathrm{g} / \mathrm{mL}$ streptomycin. Then, $100 \mu \mathrm{L}$ of A549 cells in the logarithmic growth phase at a concentration of $6 \times 10^{4}$ cells $/ \mathrm{mL}$ was seeded to each well of 96-well plates. After incubation for $24 \mathrm{~h}$, the medium was removed, and fresh, complete medium containing different concentrations of GNPs (i.e., $12.5 \mu \mathrm{g} / \mathrm{mL}, 25 \mu \mathrm{g} / \mathrm{mL}, 50 \mu \mathrm{g} / \mathrm{mL}, 100 \mu \mathrm{g} / \mathrm{mL}, 200 \mu \mathrm{g} / \mathrm{mL}$, and $400 \mu \mathrm{g} / \mathrm{mL}$ ) was added to each well. The cells were then incubated with GNPs for $48 \mathrm{~h}$. After removing the medium and washing with PBS twice, $50 \mu \mathrm{L}$ of the complete medium and $50 \mu \mathrm{L}$ of the CellTiter-Glo ${ }^{\circledR}$ assay working fluid were added in sequence. After gently shaking for 2 min, the plates were incubated for $10 \mathrm{~min}$ at room temperature in the dark. Then, $70 \mu \mathrm{L}$ of the mixture solutions in each well were transferred to another set of white, opaque 96-well plates, and the fluorescence signal intensity was detected by a plate reader (VICTORTM X2, Perkin Elmer, Waltham, MA, USA). Deducting the background signals, cell viability was calculated. Each experiment was done in parallel three times. 


\subsection{Cellular Oxidative Stress Test}

A549 cells were seeded in 24 -well plates $\left(6 \times 10^{4}\right.$ cells/well). After $24 \mathrm{~h}$ incubation, the medium in each well was removed. GNPs in cell culture medium $(500 \mu \mathrm{L}, 50 \mu \mathrm{g} / \mathrm{mL})$ were added to each well and incubated with cells for $24 \mathrm{~h}$. The cells were then washed with PBS twice and 2,7-dichlorodihydro-fluoresceindiacetate (DCFH-DA, $10 \mu \mathrm{M}$ ) in medium were added. After incubation for $30 \mathrm{~min}$ in the darkness, cells were washed with PBS three times, treated with trypsin, and collected for measurements with a fluorescence microplate reader. Groups with only cell culture medium added and $\mathrm{H}_{2} \mathrm{O}_{2}(500 \mathrm{nM})$ were set as negative and positive controls, respectively. Cellular oxidative stress was determined using the DCFH-DA method. In the absence of GNPs, cellular oxidative stress values with and without $\mathrm{H}_{2} \mathrm{O}_{2}$ were used as positive and negative controls.

\subsection{Cell Uptake Experiment}

A549 cells in the logarithmic growth phase were seeded in 24-well plates with a density of $4 \times 10^{5}$ cells/well. After $24 \mathrm{~h}$ incubation at $37^{\circ} \mathrm{C}$, each well was washed twice with $500 \mu \mathrm{L}$ of pre-warmed, serum-free RPMI1640 medium. Then, $500 \mu \mathrm{L}$ of RPMI1640 complete medium containing $50 \mu \mathrm{g} / \mathrm{mL}$ GNPs was added to each well.

After another $24 \mathrm{~h}$ incubation at $37^{\circ} \mathrm{C}$, each well was washed three times with cold PBS and $200 \mu \mathrm{L}$ of trypsin was added to each well. After 4 min digestion, $200 \mu \mathrm{L}$ of the RPMI1640 complete medium was added to stop this process. Cells in each well were counted and $200 \mu \mathrm{L}$ of the cells was collected. Fresh aqua regia was then added to completely digest the GNPs overnight at $37^{\circ} \mathrm{C}$. After diluting, gold contents in each well were measured using ICP-MS. Each experiment was done in parallel three times.

\subsection{Determination of Redox Reactivity of GNPS}

The hydrogenation ability of GNPs was evaluated by electrocatalysis of $\mathrm{H}_{2} \mathrm{O}_{2}$ to $\mathrm{OH}^{-}$ using an electrochemical workstation (CHI660c, CH Instruments, Inc.). A glassy carbon electrode was used as the working electrode, the Pt electrode as the counter electrode and the $\mathrm{Ag} / \mathrm{AgCl}$ electrode as the reference electrode. Each GNP from the library with the same concentration $(1.0 \mathrm{mg} / \mathrm{mL}, 10 \mu \mathrm{L})$ was added to the polished glassy carbon electrodes. The electrochemical reactions were performed in a $0.01 \mathrm{M}$ PBS solution with $0.3 \%, 0.6 \%$ and $0.9 \% \mathrm{H}_{2} \mathrm{O}_{2}$ at a scan rate of $20 \mathrm{mV} \cdot \mathrm{s}^{-1}$. The initial potential, the maximum potential and the minimum potential were set at $0 \mathrm{~V}, 0.6 \mathrm{~V}$ and $-1.4 \mathrm{~V}$, respectively.

\subsection{Correlation Analysis}

Based on the definition of the Pearson correlation coefficient, the correlation between different characteristics (physical and chemical properties, biological effects) of GNPs (quotient of covariance and standard deviation between different characteristics) was calculated, and the correlation degree between these characteristics was analyzed.

$$
\rho_{X, Y}=\frac{\operatorname{cov}(X, Y)}{\sigma X \sigma Y}
$$

\subsection{Structure Activity Relationship}

To explore the quantitative relationships between the nanostructures and the redox properties of GNPs, we used the structural information (i.e., Dragon descriptors) of the surface ligands to develop a quantitative structure-activity relationship (QSAR) model to predicting their redox reactivities. Here, we used a multiple linear regression method, called the least absolute shrinkage and selection operator (LASSO) model, to build the QSAR model. As a classic machine learning method, LASSO can enhance the prediction accuracy and interpretability of the resulting models through performing both variable selection and regularization. In the present LASSO model, the regularization parameter was set to 0.0001 and the maximum number of iterations set to 100,000 . As a result, a total of 58 descriptors were selected to fit the model. Both model construction and prediction were 
performed by the machine learning library in Python, scikit-learn v0.19.2. The correlation between experimental and predicted reduction activity values is shown in Figure 3c. The high determination coefficient $(\mathrm{R} 2=0.82)$ showed that the machine learning model correctly predicted GNPs' redox activities.

\section{Conclusions}

In this study, we explored the induction of cytotoxicity by a combinatorial GNP library with diverse redox activity. In this systematic work, we established that the cytotoxicity was directly caused by the oxidative reactivity, rather than other properties, of GNPs. There are two important implications of this study. First, a simple electrochemical characterization of nanoparticles should in the future be used to predict the basic toxicity risk of nanoparticles. Second, screening of a GNP library yields an array of nanoprobes, which can be embedded into human cells to probe cellular mechanisms or generate cell models with various oxidative stresses. Both of these findings will accelerate nanomedicine and nanotoxicity studies significantly. Through regulation of redox activity, GNPs may regulate cells to the appropriate level of oxidative stress to enforce a synergistic effect, which may further enhance the applications of GNPs in more biomedical fields, such as imaging, drug delivery, diagnosis and clinical treatment.

Supplementary Materials: The following are available online. Figure S1: TEM images of 80 GNPs in the whole library. Figure S2: The characterization of physicochemical properties and biological effects of 80 GNPs in the whole library. Figure S3: When the ligand does not contain ferrocene substituents, GNPs do not show obvious redox activity. Figure S4: The redox activities of 80 GNPs in the whole library were characterized by cyclic voltammetry. Figure S5: The dose response curves of 80 GNPs in the whole library. Figure S6: The relationship between the redox activity of 80 GNPs and their hydrodynamic diameter or number of ligand uploads. Figure S7: The relationship between the cellular effects of $80 \mathrm{GNPs}$ and hydrophobic property or surface charge.

Author Contributions: B.Y. conceived the idea. B.Y. and S.W. designed the experiments; S.W. and X.Y. conducted the research; B.Y., S.W., X.Y. and G.S. analyzed and interpreted the data; B.Y., X.Y., G.S. and S.W. wrote and edited the manuscript. All authors have read and agreed to the published version of the manuscript.

Funding: This research was funded by the National Key R\&D Program of China (2016YFA0203103), the National Natural Science Foundation of China (22036002 and 22076085), and the innovative R\&D team project introduced under the "Pearl River Talent Recruitment Program" of Guangdong Province (2019ZT08L387).

Institutional Review Board Statement: Not applicable.

Informed Consent Statement: Not applicable.

Data Availability Statement: Supplemental data are provided in the Supplementary Materials, Figures S1-S6.

Acknowledgments: We thank Xue Bai, Fang Liu and Guohong Liu for their technical assistance.

Conflicts of Interest: The authors declare no conflict of interest.

Ethical Statements: A549 cells were used following all regulations on human cell line usage. The A549 cells were obtained from ATCC. There was no violation of laws, regulations or ethical guidelines in the cell experiments.

Sample Availability: Samples of the compounds and nanoparticles are available from the authors.

\section{Abbreviations}

DMF N,N-Dimethylformamide

GNP Gold nanoparticle

ICP-MS Inductively coupled plasma massspectrometry

PBS Phosphate Buffered Saline 


$\begin{array}{ll}\text { SHE } & \text { Standard hydrogen electrode } \\ \text { TEM } & \text { Transmission Electron Microscope } \\ \text { TLC } & \text { Thin Layer Chromatography }\end{array}$

\section{References}

1. Aufaure, R.; Lalatonne, Y.; Lièvre, N.; Heintz, O.; Motte, L.; Guénin, E. One pot microwave assisted synthesis of bisphosphonate alkene capped gold nanoparticles. RSC Adv. 2014, 4, 59315-59322. [CrossRef]

2. Wang, X.; Li, J.; Wang, Y.; Koenig, L.; Gjyrezi, A.; Giannakakou, P.; Shin, E.H.; Tighiouart, M.; Chen, Z.G.; Nie, S.; et al. A Folate Receptor-Targeting Nanoparticle Minimizes Drug Resistance in a Human Cancer Model. ACS Nano 2011, 5, 6184-6194. [CrossRef] [PubMed]

3. Van Haute, D.; Liu, A.T.; Berlin, J.M. Coating Metal Nanoparticle Surfaces with Small Organic Molecules Can Reduce Nonspecific Cell Uptake. ACS Nano 2018, 12, 117-127. [CrossRef]

4. Del Pino, P.; Yang, F.; Pelaz, B.; Zhang, Q.; Kantner, K.; Hartmann, R.; Martinez de Baroja, N.; Gallego, M.; Möller, M.; Manshian, B.B.; et al. Basic Physicochemical Properties of Polyethylene Glycol Coated Gold Nanoparticles That Determine Their Interaction with Cells. Angew. Chem. Int. Ed. 2016, 128, 5573-5577. [CrossRef]

5. Dheyab, M.A.; Aziz, A.A.; Jameel, M.S.; Abu Noqta, O.; Mehrdel, B. Synthesis and coating methods of biocompatible iron oxide/gold nanoparticle and nanocomposite for biomedical applications. Chin. J. Phys. 2020, 64, 305-325. [CrossRef]

6. Yoon, Y.J.; Kang, S.H.; Do, C.; Moon, S.Y.; Kim, T.H. Water-Redispersible and Highly Stable Gold Nanoparticles Permanently Capped by Charge-Controllable Surfactants for Potential Medical Applications. ACS Appl. Nano Mater. 2019, 2, 7924-7932. [CrossRef]

7. Penders, J.; Stolzoff, M.; Hickey, D.J.; Andersson, M.; Webster, T.J. Shape-dependent antibacterial effects of non-cytotoxic gold nanoparticles. Int. J. Nanomed. 2017, 12, 2457-2468. [CrossRef]

8. Huang, H.; Du Toit, H.; Ben Jaber, S.; Wu, G.; Panariello, L.; Thanh, N.T.K.; Parkin, I.P.; Gavriilidis, A. Rapid synthesis of gold nanoparticles with carbon monoxide in a microfluidic segmented flow system. React. Chem. Eng. 2019, 4, 884-890. [CrossRef]

9. Tiwari, P.M.; Vig, K.; Dennis, V.A.; Singh, S.R. Functionalized Gold Nanoparticles and Their Biomedical Applications. Nanomaterials 2011, 1, 31-63. [CrossRef]

10. Mieszawska, A.J.; Mulder, W.J.M.; Fayad, Z.A.; Cormode, D.P. Multifunctional Gold Nanoparticles for Diagnosis and Therapy of Disease. Mol. Pharm. 2013, 10, 831-847. [CrossRef]

11. Wang, L.; Natan, M.; Zheng, W.; Zheng, W.; Liu, S.; Jacobi, G.; Perelshtein, I.; Gedanken, A.; Banin, E.; Jiang, X. Small moleculedecorated gold nanoparticles for preparing antibiofilm fabrics. Nanoscale Adv. 2020, 2, 2293-2302. [CrossRef]

12. Fernandes, A.R.; Baptista, P.V. Gene Silencing Using Multifunctionalized Gold Nanoparticles for Cancer Therapy. Methods Mol. Biol. 2017, 1530, 319-336. [PubMed]

13. Daniel, M.C.; Astruc, D. Gold nanoparticles: Assembly, supramolecular chemistry, quantum-size-related properties, and applications toward biology, catalysis, and nanotechnology. Chem. Rev. 2004, 104, 293-346. [CrossRef] [PubMed]

14. Ryou, S.M.; Kim, J.M.; Yeom, J.H.; Hyun, S.; Kim, S.; Han, M.S.; Kim, S.W.; Bae, J.; Rhee, S.; Lee, K. Gold Nanoparticle-Assisted Delivery of Small, Highly Structured RNA into the Nuclei of Human Cells. Biochem. Biophys. Res. Commun. 2011, 416, 178-183. [CrossRef] [PubMed]

15. Bai, X.; Wang, S.; Yan, X.; Zhou, H.; Yan, B. Regulation of cell uptake and cytotoxicity by nanoparticle core under the controlled shape, size, and surface chemistries. ACS Nano 2020, 14, 289-302. [CrossRef]

16. Burrows, N.D.; Lin, W.; Hinman, J.G.; Dennison, J.; Vartanian, A.M.; Abadeer, N.S.; Grzincic, E.M.; Jacob, L.M.; Li, J.; Murphy, C.J. The Surface Chemistry of Gold Nanorods. Langmuir 2016, 32, 9905-9921. [CrossRef] [PubMed]

17. Song, J.; Pu, L.; Zhou, J.; Duan, B.; Duan, H. Biodegradable Theranostic Plasmonic Vesicles of Amphiphilic Gold Nanorods. ACS Nano 2013, 7, 9947-9960. [CrossRef] [PubMed]

18. Grzincic, E.M.; Murphy, C.J. Gold Nanorods Indirectly Promote Migration of Metastatic Human Breast Cancer Cells in ThreeDimensional Cultures. ACS Nano 2015, 9, 6801-6816. [CrossRef]

19. Giljohann, D.A.; Seferos, D.S.; Daniel, W.L.; Massich, M.D.; Patel, P.C.; Mirkin, C.A. Gold nanoparticles for biology and medicine. Angew. Chem. Int. Ed. 2010, 49, 3280-3294. [CrossRef]

20. Kim, J.H.; Yeom, J.H.; Ko, J.J.; Han, M.S.; Lee, K.; Na, S.Y.; Bae, J. Effective Delivery of Anti-MiRNA DNA Oligonucleotides by Functionalized Gold Nanoparticles. J. Biotechnol. 2011, 155, 287-292. [CrossRef] [PubMed]

21. Boisselier, E.; Astruc, D. Gold nanoparticles in nanomedicine: Preparations, imaging, diagnostics, therapies and toxicity. Chem. Soc. Rev. 2009, 38, 1759-1782. [CrossRef]

22. Zhou, H.; Jiao, P.; Yang, L.; Li, X.; Yan, B. Enhancing Cell Recognition by Scrutinizing Cell Surfaces with a Nanoparticle Array. J. Am. Chem. Soc. 2011, 133, 680-682. [CrossRef]

23. Liu, Y.; Winkler, D.A.; Epa, V.C.; Zhang, B.; Yan, B. Probing Enzyme-Nanoparticle Interactions Using Combinatorial Gold Nanoparticle Libraries. Nano Res. 2015, 8, 1293-1308. [CrossRef]

24. Wu, L.; Zhang, Y.; Zhang, C.; Cui, X.; Zhai, S.; Liu, Y.; Li, C.; Zhu, H.; Qu, G.; Jiang, G.; et al. Tuning Cell Autophagy by Diversifying Carbon Nanotube Surface Chemistry. ACS Nano 2014, 8, 2087-2099. [CrossRef] 
25. Ludwig, B.S.; Tomassi, S.; Maro, S.D.; Di Leva, F.S.; Benge, A.; Reichart, F.; Nieberler, M.; Kühn, F.E.; Kessler, H.; Marinelli, L. The organometallic ferrocene exhibits amplified anti-tumor activity by targeted delivery via highly selective ligands to $\alpha \vee \beta 3, \alpha \vee \beta 6$, or $\alpha 5 \beta 1$ integrins. Biomaterials 2021, 271, 120754. [CrossRef] [PubMed]

26. Lai, H.W.; Liu, Z.Q. Thiaflavan scavenges radicals and inhibits DNA oxidation: A story from the ferrocene modification. Eur. J. Med. Chem. 2014, 81, 227-236. [CrossRef]

27. Liu, Z.-Q. Enhancing Antioxidant Effect against Peroxyl Radical-induced Oxidation of DNA: Linking with Ferrocene Moiety! Chem. Rec. 2019, 19, 2385-2397. [CrossRef]

28. Zhou, W.; Gao, X.; Liu, D.; Chen, X. Octanol/water partition coefficient of selected herbicides: Determination using shake-flask method and reversed-phase high-performance liquid chromatography. J. Chem. Eng. Data 2004, 49, 1639-1642.

29. Qiao, Y.; Xia, S.; Ma, P. Octanol/water partition coefficient of substituted benzene derivatives containing halogens and carboxyls: Determination using the shake-flask method and estimation using the fragment method. J. Chem. Eng. Data 2008, 53, 280-282. [CrossRef]

30. Li, S.; Zhai, S.; Liu, Y.; Zhou, H.; Wu, J.; Jiao, Q.; Zhang, B.; Zhu, H.; Yan, B. Experimental Modulation and Computational Model of Nano-Hydrophobicity. Biomaterials 2015, 52, 312-317. [CrossRef]

31. Peña-González, C.E.; García-Broncano, P.; Ottaviani, M.F.; Cangiotti, M.; Fattori, A.; Hierro-Oliva, M.; González-Martín, M.L.; Pérez-Serrano, J.; Gómez, R.; Muñoz-Fernández, M.Á.; et al. Dendronized Anionic Gold Nanoparticles: Synthesis, Characterization, and Antiviral Activity. Chem. A Eur. J. 2016, 22, 2987-2999. [CrossRef] [PubMed]

32. Kister, T.; Monego, D.; Mulvaney, P.; Widmer-Cooper, A.; Kraus, T. Colloidal Stability of Apolar Nanoparticles: The Role of Particle Size and Ligand Shell Structure. ACS Nano 2018, 12, 5969-5977. [CrossRef] [PubMed]

33. Fisher, E.A.; Duffy, S.J.; Meli, M.V. The Determination of Ligand Shell Composition of Bifunctional Alkanethiol-capped Gold Nanoparticles using GC/MS/MS. RSC Adv. 2015, 5, 33289-33293. [CrossRef]

34. Galaris, D.; Skiada, V.; Barbouti, A. Redox Signaling and Cancer: The Role of "Labile" Iron. Cancer Lett. 2008, 266, 21-29. [CrossRef] [PubMed]

35. Lin, M.T.; Beal, M.F. Mitochondrial Dysfunction and Oxidative Stress in Neurodegenerative Diseases. Nature 2006, 443, 787-795. [CrossRef] [PubMed]

36. Dickinson, B.C.; Chang, C.J. Chemistry and Biology of Reactive Oxygen Species in Signaling or Stress Responses. Nat. Chem. Biol. 2011, 7, 504-511. [CrossRef] [PubMed]

37. Finkel, T. Signal Transduction by Reactive Oxygen Species. J. Cell Biol. 2011, 194, 7-15. [CrossRef]

38. Prasad, S.; Gupta, S.C.; Tyagi, A.K. Reactive Oxygen Species (ROS) and Cancer: Role of Antioxidative Utraceuticals. Cancer Lett. 2017, 3835, 95-105. [CrossRef]

39. Wu, Z.; Du, Y.; Xue, H.; Wu, Y.; Zhou, B. Aluminum Induces Neurodegeneration and Its Toxicity Arises from Increased Iron Accumulation and Reactive Oxygen Species (ROS) Production. Neurobiol. Aging 2012, 33, 199.e1-199.e12. [CrossRef]

40. Kaneto, H.; Katakami, N.; Matsuhisa, M.; Matsuoka, T.-A. Role of Reactive Oxygen Species in the Progression of Type 2 Diabetes and Atherosclerosis. Mediat. Inflamm. 2010, 2010, 1-11. [CrossRef]

41. Thakor, A.S.; Paulmurugan, R.; Kempen, P.; Zavaleta, C.; Sinclair, R.; Massoud, T.F.; Gambhir, S.S. Oxidative Stress Mediates the Effects of Raman-Active Gold Nanoparticles in Human Cells. Small 2011, 7, 126-136. [CrossRef]

42. Vijay, S.; Gauthier, J.A.; Heenen, H.H.; Chan, K. Dipole-Field Interactions Determine the $\mathrm{CO}_{2}$ Reduction Activity of 2D Fe-N-C Single-Atom Catalysts. ACS Catal. 2020, 10, 7826-7835. [CrossRef]

43. Fu, J.; Zhu, B.; Jiang, C.; Cheng, B.; You, W.; Yu, J. Hierarchical porous O-doped g- $\mathrm{C}_{3} \mathrm{~N}_{4}$ with enhanced photocatalytic $\mathrm{CO}_{2}$ reduction activity. Small 2017, 13, 1603938. [CrossRef]

44. Chompoosor, A.; Saha, K.; Ghosh, P.S.; Macarthy, D.J.; Miranda, O.R.; Zhu, Z.-J.; Arcaro, K.F.; Rotello, V.M. The Role of Surface Functionality on Acute Cytotoxicity, ROS Generation and DNA Damage by Cationic Gold Nanoparticles. Small 2010, 6, $2246-2249$. [CrossRef] [PubMed]

45. Tian, B.; Li, J.; Pang, R.; Dai, S.; Li, T.; Weng, Y.; Jin, Y.; Hua, Y. Gold Nanoparticles Biosynthesized and Functionalized Using a Hydroxylated Tetraterpenoid Trigger Gene Expression Changes and Apoptosis in Cancer Cells. ACS Appl. Mater. Interfaces 2018, 10, 37353-37363. [CrossRef] [PubMed]

46. Beik, J.; Khateri, M.; Khosravi, Z.; Kamrava, S.K.; Kooranifar, S.; Ghaznavi, H.; Shakeri-Zadeh, A. Gold Nanoparticles in Combinatorial Cancer Therapy Strategies. Coord. Chem. Rev. 2019, 387, 299-324.

47. Dreaden, E.C.; Alkilany, A.M.; Huang, X.; Murphy, C.J.; El-Sayed, M.A. The golden age: Gold nanoparticles for biomedicine. Chem. Soc. Rev. 2012, 41, 2740-2779. [CrossRef] [PubMed]

48. Conde, J.; Ambrosone, A.; Sanz, V.; Hernandez, Y.; Marchesano, V.; Tian, F.; Child, H.; Berry, C.C.; Ibarra, M.R.; Baptista, P.V.; et al. Design of Multifunctional Gold Nanoparticles for in Vitro and in Vivo Gene Silencing. ACS Nano 2012, 6, 8316-8324. [CrossRef] [PubMed]

49. Zhou, W.; Gao, X.; Liu, D.; Chen, X. Gold nanoparticles for in vitro diagnostics. Chem. Rev. 2015, 115, 10575-10636. [CrossRef] [PubMed]

50. Jin, Y.; Li, H.; Bai, J. Homogeneous selecting of a quadruplex-binding ligand-based gold nanoparticle fluorescence resonance energy transfer assay. Anal. Chem. 2009, 81, 5709-5715. [CrossRef] 
51. Yin, B.C.; Zuo, P.; Huo, H.; Zhong, X.; Ye, B.C. Dnazyme self-assembled gold nanoparticles for determination of metal ions using fluorescence anisotropy assay. Anal. Biochem. 2010, 401, 47-52. [CrossRef] [PubMed]

52. Sun, H.; Liu, Y.; Bai, X.; Zhou, X.; Zhou, H.; Liu, S.; Yan, B. Induction of oxidative stress and sensitization of cancer cells to paclitaxel by gold nanoparticles with different charge densities and hydrophobicities. J. Mater. Chem. B 2018, 6, 1633-1639. [CrossRef] [PubMed] 